\title{
Jean Wauquelin, La Manequine
}

\section{Paola Cifarelli}

\section{(2) OpenEdition \\ Journals}

\section{Édition électronique}

URL : http://journals.openedition.org/studifrancesi/5544

DOI : 10.4000/studifrancesi.5544

ISSN : 2421-5856

\section{Éditeur}

Rosenberg \& Sellier

\section{Édition imprimée}

Date de publication : 1 septembre 2011

Pagination : 389-390

ISSN : 0039-2944

\section{Référence électronique}

Paola Cifarelli, « Jean Wauquelin, La Manequine », Studi Francesi [En ligne], 164 (LV | II) | 2011, mis en ligne le 30 novembre 2015, consulté le 07 janvier 2021. URL : http://journals.openedition.org/ studifrancesi/5544 ; DOI : https://doi.org/ERREUR PDO dans /localdata/www-bin/Core/Core/Db/ Db.class.php L.34 : SQLSTATE[HY000] [2006] MySQL server has gone away

Ce document a été généré automatiquement le 7 janvier 2021.

\section{(c) (i) ()}

Studi Francesi è distribuita con Licenza Creative Commons Attribuzione - Non commerciale - Non opere derivate 4.0 Internazionale. 


\title{
Jean Wauquelin, La Manequine
}

\author{
Paola Cifarelli
}

\section{RÉFÉRENCE}

JEAN WAUQUelin, La Manequine, édition de maria Colombo timelli, Paris, Éditions Classiques Garnier, 2010 («Textes littéraires du Moyen Âge» 13 - série «Mises en prose» 1), 334 pp.

1 Voilà une édition critique impeccable, et exemplaire sous plusieurs points de vue, du texte que Jean Wauquelin rédigea avant 1448, à partir du roman en vers de Philippe de Remi. Conservée dans le manuscrit unique de la Biblioteca Nazionale Universitaria de Turin (L.IV.5), cette mise en prose dédiée au fonctionnaire de la cour de Bourgogne Jean de Croÿ a retenu l'attention de la critique à plusieurs reprises et elle avait été éditée par H. Suchier en 1884; toutefois, une nouvelle édition qui permettrait de mieux appréhender le texte d'un point de vue codicologique, philologique, linguistique et littéraire était non seulement souhaitable, mais nécessaire.

2 Dans l'introduction, le lecteur trouvera, après la description du manuscrit restauré après l'incendie de 1904 et les informations concernant auteur et dédicataire de l'œuvre, une mise au point bibliographique qui fournit tous les renseignements sur la fortune critique du texte en prose et de son hypotexte en vers. Ensuite, dans l'Analyse, la matière de ce récit est exposée de manière synthétique, tandis que les pages consacrées à $L a$ Réécriture de Wauquelin sont focalisées sur les aspects plus proprement stylistiques et littéraires du texte. L'étude du paratexte (prologue et épilogue) par rapport aux textes liminaires d'autres œuvres du même auteur permet de mettre l'accent sur les traits caractéristiques de la personnalité de celui-ci, qui se manifeste aussi dans les interventions sur l'organisation de la matière; son découpage en unités narratives, relevé par l'utilisation de titres de chapitre et par des stratégies linguistiques particulières pour les attaques de chapitre, trahissent la volonté du prosateur de marquer sa présence, tout comme l'utilisation d'anticipations, transitions et commentaires dans le corps du texte. Tous les procédés utilisés - attestations de fidélité à la source, commentaires, insertion de citations latines et de proverbes - font 
l'objet d'une analyse pénétrante qui met en relief la primauté de la recherche de cohésion du récit chez l'auteur. L'observation des techniques dont Wauquelin se sert dans le chapitre XLVIII pour adapter en prose le texte source a comme but de cerner les 'règles' d'une pratique d'écriture, autrement dit le fonctionnement de ce qu'on pourrait appeler une 'grammaire' de la mise en prose; celle-ci concerne aussi bien les interventions sur le récit au moyen de coupures, d'ajouts et de petites modifications visant surtout à accentuer le réalisme et la cohérence, que le traitement de quelques motifs privilégiés: le temps, l'espace, l'échange épistolaire, la foi de l'héroïne.

Dans l'Étude linguistique, M.C.T. analyse de manière approfondie la langue du texte, teintée de traits dialectaux septentrionaux; graphie et phonétique, morpho-syntaxe, lexique sont examinés de façon exhaustive, ce qui permet au lecteur d'avoir une idée très précise des caractéristiques propres à la langue de l'auteur. La section consacrée aux Traits stylistiques permet de compléter cette description.

4 Le texte, transcrit très soigneusement, et son apparat critique sont accompagnés de notes portant aussi bien sur des questions proprement philologiques que sur des détails linguistiques et littéraires; l'utilisation critique d'une vaste bibliographie dans cette partie de l'ouvrage rend cette notation particulièrement éclairante, tandis que la confrontation ponctuelle avec l'hypotexte permet de cerner exactement les techniques mises en œuvre par le prosateur et de suivre au fil du texte ses interventions. Le glossaire, qui fait une large place aux locutions et autres formes figées, se signale par son ampleur, sa richesse et sa précision.

5 Les index-nominum, locorum, des personnifications - et les tables qui complètent l'édition - foliotation du manuscrit, rapport vers-lignes dans les deux versions du récit, enluminures et chapitres, titres de chapitres, attaques de ceux-ci, interventions du narrateur, citations et proverbes, épîtres - constituent des aides importantes pour ceux qui se serviront de cette édition pour des études plus vastes et transversales.

Véritable exemple de l'application d'une méthodologie d'édition propre aux mises en prose, la Manequine inaugure dignement une collection qui pourra sans doute remplir de façon excellente les vides qui marquent encore ce domaine de la littérature en moyen français. 